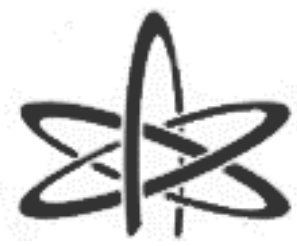

BJRS
BRAZILIAN JOURNAL

$\mathrm{OF}$

RADIATION SCIENCES

07-02A (2019) 01-10

\title{
Upgrading safety systems of industrial irradiation
}

\section{facilities}

\author{
R. S. Gomes ${ }^{a}$, J. D. R. L. Gomes ${ }^{a}$, E. L. C. Costa ${ }^{a}$,M. L. L. Costa ${ }^{a}$, Z. D. Thoméb \\ ${ }^{a}$ Comissão Nacional de Energia Nuclear/Diretoria de Radioproteção e Segurança Nuclear, 22290-901, Rio de Janeiro,
} RJ, Brasil

${ }^{b}$ Instituto Militar de Engenharia/Seção de Engenharia Nuclear, 22291-270, Rio de Janeiro, RJ, Brasil

rogeriog@cnen.gov.br

\begin{abstract}
The first industrial irradiation facility in operation in Brazil was designed in the 70s. Nowadays, twelve commercial and research facilities are in operation and two already decommissioned. Minor modifications and upgrades, as sensors replacement, have been introduced in these facilities, in order to reduce the technological gap in the control and safety systems. The safety systems are designed in agreement with the codes and standards at the time. Since then, new standards, codes and recommendations, as well as lessons learned from accidents, have been issued by various international committees or regulatory bodies. The rapid advance of the industry makes the safety equipment used in the original construction become obsolete. The decreasing demand for these older products means that they are no longer produced, which can make it impossible or costly to obtain spare parts and the expansion of legacy systems to include new features. This work aims to evaluate existing safety systems at Brazilian irradiation facilities, mainly the oldest facilities, taking into account the recommended IAEA's design requirements. Irrespective of the fact that during its operational period no event with victims have been recorded in Brazilian facilities, and that the regulatory inspections do not present any serious deviations regarding the safety procedures, it is necessary an assessment of safety system with the purpose of bringing their systems to "the state of the art", avoiding their rapid obsolescence. This study has also taken into account the knowledge, concepts and solutions developed to upgrading safety system in irradiation facilities throughout the world.
\end{abstract}

Keywords: Safety system, Irradiation facilities, Licensing 


\section{INTRODUCTION}

Industrial irradiators are large facilities that use high doses of ionizing radiation for the purpose of modifying the physical, chemical and biological properties of irradiated materials. These facilities generally use Cobalt-60 radioactive sources (or electron beams) for sterilization of food, pharmaceuticals products and medical-surgical equipment.

Between 1974 and 2008 several accidents, with fatalities, were registered in industrial irradiation facilities [1] [2] [3] [4], as shown in table 1. These accidents have generated lessons that have been applied in modifications to the design of safety systems and operating procedures, as well as modifications in the licensing processes with the aim of to preventing similar accidents in the future or to mitigate their consequences.

The accidents that occurred in irradiation facilities have demonstrated that these facilities have safetycritical systems, whose failure could result in loss of life, significant property damage, or environmental harm. The IAEA provide specific and practical recommendations on the safe design and operation of irradiations facilities, for use by operating organizations, the designers of these facilities and by regulatory bodies [5].

Table 1. List of accidents at irradiation facilities

\begin{tabular}{lcccc}
\hline Year & Local & Dead & Injured & Doses (Gy) \\
\hline 1974 & Parsippany (USA) & 0 & 3 & $1-6$ \\
1975 & Stimos (Italy) & 1 & 0 & 12 \\
1977 & New Jersey (USA) & 0 & 1 & 2 \\
1982 & Kjeller (Norway) & 1 & 0 & 22 \\
1989 & San Salvador (El Salvador) & 1 & 2 & 8 \\
1990 & Soreq (Israel) & 1 & 0 & $10-20$ \\
1990 & Shangai (China) & 2 & 0 & $11-12$ \\
1991 & Nesvizh (Belarus) & 1 & 0 & 11 \\
2004 & Shandong (China) & 2 & 0 & $8-20$ \\
2006 & Fleurus (Belgium) & 0 & 1 & $4.2-4.8$ \\
2008 & Shanxi (China) & 2 & 3 & $1.7-14.5$ \\
\hline
\end{tabular}


The primary reason for deciding to upgrade a safety system is in the eventual obsolescence of the equipment. Obsolescence of embedded parts is a serious concern for management of complex systems where the design life of the system typically exceeds 20 years, thus, a process for reviewing the obsolescence of structures, systems and components important to safety should be in place, identifying threats from obsolescence and ensure that an adequate supply of spare parts is available until a solution to any obsolescence issues can be found [7].

Normally, facilities upgrade their safety systems for a variety of reasons, among the most important are [8]:

- Equipment obsolescence - Equipment often becomes obsolete when their components are no longer manufactured, thus, the ongoing maintenance and support of these systems will no longer be viable once the supplier support infrastructure can no longer service the equipment.

- Erroneous operation - As safety system components age, they will no longer perform within their designed parameters, so part of the system may begin to operate erroneously. Thus, the safety system often may be activated, resulting in unnecessary and costly shutdowns.

- Inability to expand or enhance the system - Legacy systems are difficult to expand, beyond small changes. Therefore, expansion to accommodate new features, resulting from new standards, codes and recommendations, as well as lessons learned from accidents, is often difficult to accommodate due to physical space and system interface constraints. In addition, older systems may not meet current industry standards.

\section{IRRADIATION FACILITIES IN BRAZIL}

The first industrial irradiation facility in operation in Brazil was designed in the 70s. Nowadays, twelve facilities are licensed and in operation, with maximum activity up to $5 \mathrm{MCi}$ (185 PBq), and two facilities already decommissioned.

There is no specific standard for the licensing of industrial irradiation facilities in Brazil, thus the generic CNEN's standards related with the licensing of these facilities are CNEN-NN-3.01 [9], CNEN-NE-3.02 [10] and CNEN-NN-6.02 [11].

After their licensing, only minor modifications and upgrades, as sensors replacement, have been introduced in oldest facilities, in order to reduce the technological gap in the control and safety systems.

Irrespective of the fact that during its operational period no event with victims have been recorded in Brazilian facilities, and that the safety records, obtained during regulatory inspections, does not present any serious deviations, it is necessary an assessment of their safety system with the purpose 
of bringing their systems to "the state of the art" avoiding their rapid obsolescence, mainly due to the potential for accidents with serious consequences for this industry.

According the IAEA [5], the irradiation facilities can be defined on the basis of its design and, in particular, the accessibility and shielding of the radioactive source. For gamma irradiators: Category I facilities being self-shielded irradiators; Category II concerning panoramic dry source storage irradiators; Category III are underwater irradiators and Category IV irradiators are panoramic wet source storage irradiators. A similar categorization may be applied to irradiators utilizing electron beam, with Category I irradiators being integrally shielded units and Category II units are housed in shielded rooms which are kept inaccessible during operation by means of an entry control system [5] [6]. The number of facilities in operation in Brazil can be categorized as shown in table 2:

Table 2. Number of irradiation facilities in Brazil

\begin{tabular}{ccccc}
\hline Category & I & II & III & IV \\
\hline $\begin{array}{c}\text { Gamma } \\
\text { Irradiators }\end{array}$ & $\begin{array}{c}\text { They are not } \\
\text { within the } \\
\text { scope } \\
\text { of this study }\end{array}$ & 3 & 0 & 5 \\
Irradiators & 3 & - & - \\
\hline
\end{tabular}

It should be emphasized that the gamma or electron beam irradiation facilities included in Category I they are not within the scope of this study.

\section{RESULTS}

The main safety subsystems and sensors that shall be installed in irradiators facilities, assessed in this study, are shown in figure 1. Taking into account the IAEA recommendations [5], we can mention the following diagnosis of the safety systems in Brazilian irradiators, which should be observed during their upgrade, aiming to improve their safety system:

\section{Safety Instrumented System}

A safety instrumented system consists of an engineered set of hardware and software controls which are especially used on critical process systems. Normally, the technology used on control units of oldest facilities is based on electromechanical relays logic, however, nowadays programmable logic 
controllers (PLC) is widely used, being designed to replace relay control systems, once the former offers a number of advantages, mainly in costs and flexibility in making changes. The PLC provides digital I/O ports designed for interfacing with safety components such as sensors, switches, radiation monitors, pumps and graphical interfaces.

Figure 1: Main equipment and sensors of the safety system for irradiation facilities.
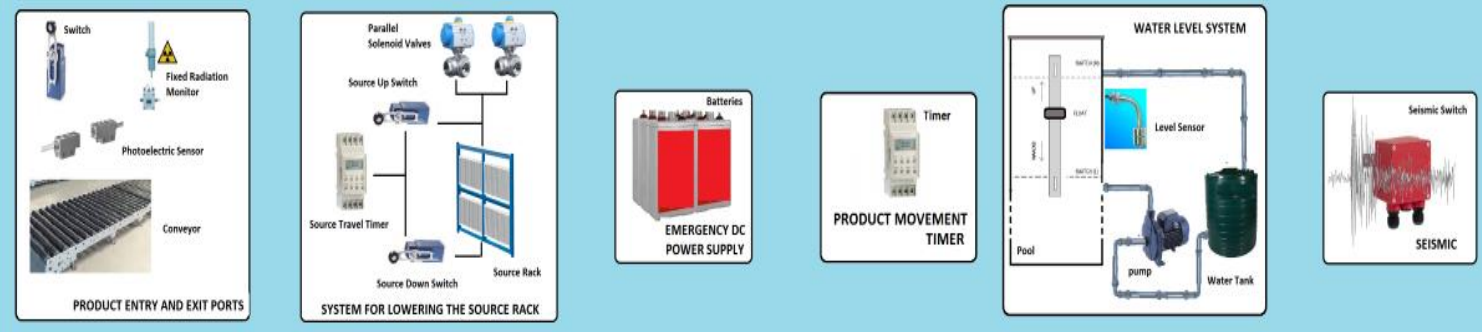

Communication Bus
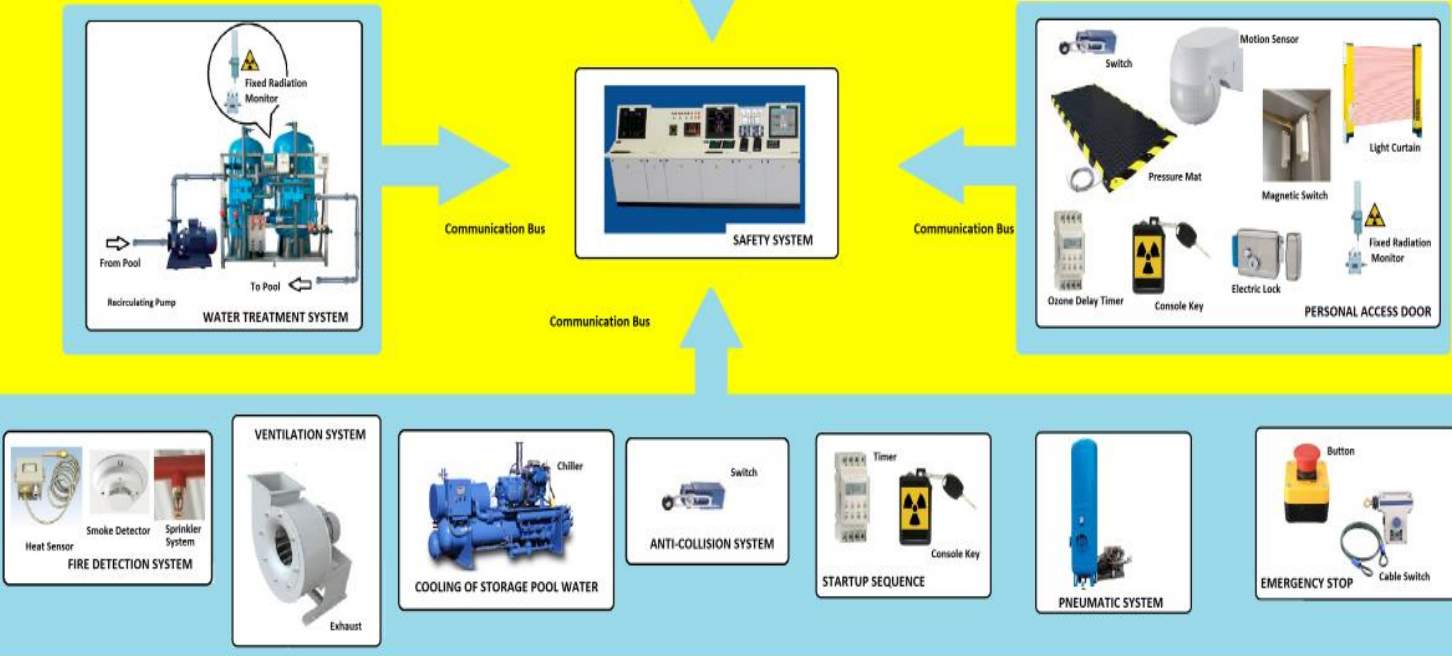

It should be emphasized that their application in safety systems requires close scrutiny, once generalpurpose (standard) PLCs were not designed for use in critical safety applications, since it does not have diagnostic capabilities, failsafe characteristics, or effective levels of redundancy, so standard PLCs offer a number of advantages, but they also have severe limitations when applied to safety.

A safety PLC, on the other hand, is a dedicated controller specifically built and certified to meet safety requirements, or the levels of risk reduction provided by some safety function. The main difference between the two types of PLCs is the presence of redundancy and self-checking mechanisms in the safety PLC that are not present in a standard PLC.

It should be noted that some upgraded irradiator facilities throughout the world use standard PLCs in safety applications can be configured in pairs (dual cross-wired PLCs) [12] [13] [14]. In this design, the redundant controller is used to support a safe and orderly shutdown of the facility when the 
primary controller fails, providing higher reliability, however systems of this type tend to be customized, and utilize extra programming, increasing the difficulty of maintenance, thus this dual approach might have made sense in the 1990s, but it's not very economical when compared against systems that are now available [7].

Thus, the selection of the appropriate system to update oldest irradiation facilities must pass through the use of safety systems based on safety PLCs, increasing their reliability.

\section{Safety and Process Control System Sharing}

The sharing of equipment and components between safety and process control systems is not prohibited, but in this case, an analysis should be carried out in order to assess if the occurrence of a common cause failure in a shared device can cause a loss of control in the industrial process and simultaneously a demand on the safety system preventing a proper shutdown action.

So, the safety system could be part of the control system but it should be fully independent and should operate in parallel. To ensure its complete independence, the safety system should have its own separate sensors. The newer Brazilian facilities have independency between safety and control system, however, for oldest facilities, it has been observed that sensors and valves are the main devices that are often shared, although no safety analysis has been performed regarding this sharing.

\section{Access Control to the Irradiation Area}

In general, in the panoramic irradiators it is possible to have access to the irradiation room through the personnel access door, the entrance and exit doors of products and through the opening in the ceiling of large irradiators. For this latter access, there are not greater differences with respect to the access control, being limited only to a safety switch, mainly because the weight of the roof plug. Generally, the plug is only opening during loading and unloading of radioactive sources.

The main accidents in irradiators involved the inadverted access of personnel during exposure of the source, thus, access control to the irradiation area is one of the most important parts of the safety system of these installations and must provide adequate redundancy and diversity in their sensors.

Regarding the personnel access door, all irradiators in Brazil have an electric lock that does not allow the opening of the door when the source is exposed. If the door is opened with the source exposed, a switch will command the return of the source to its safe position. The door key is the same that enables the startup of the facility.

The difference among the facilities is at the level of redundancy and diversity. The older ones do not have additional sensors to the access door. All the other irradiators have photoelectric sensors in the main access door, which can be single-beam emitter and receiver units or light curtains. It should be noted that none of the gamma irradiators use motion sensors or pressure mats. 
Regarding the product entry and exit ports, to disable the operation of the installation in case of access of people through the product entrance and exit doors, some installations have physical locks, either through doors that open and close to the passage of the product containers or by blocking access by the containers themselves.

With the exception of two of the irradiators in operation, all have independent photoelectric sensors in each of the product ports. In one of the Brazilian irradiators, in place of the photoelectric sensors, optoelectronic sensors are used in conjunction with proximity switches [15], which identify the dimensions of the standard container used in the facility, generating a signal for the shutdown of the irradiator if a body with different dimensions enters through these accesses. Some facilities have only physical locks at product entrance and exit ports, in order to disable the operation of the facility, in case of inadvertent entry of people through these ports, that normally open and close for the passage of the product containers.

\section{Ozone}

One of the irradiators in operation in Brazil does not have a timer in its safety system to delay the opening of the main access door, in order to reduce ozone concentration inside the irradiation room before opening the door. The delay in opening the door is performed by the operating teams of this facility only by operational procedures with the use of a manual chronometer.

Despite the IAEA recommendation not point the necessity of installation of ozone monitors in irradiation facilities, there are countries where the use of ozone monitors is mandatory [16]. The Brazilian regulatory body not determine the use of ozone monitors. The maximum ozone concentration is estimated based in mathematical calculations, and this result is used to determine the delay time to opening the main access door.

It should be noted that the safety system of all irradiators in Brazil does not allow the operation without the functioning of the exhaust system.

\section{Collision sensors}

All gamma irradiators should be provided with a guard that protects the source rack from mechanical shocks, however, few irradiators have an additional system of collision sensors that identify products that are poorly positioned in the transport system, and it may collide with the guard. The sensor generates a fault signal that must automatically disable the operation of the transport system, bringing the sources to the safe position, enabling the product rearrangement.

It should be observed that irradiators manufacturers point that this sensor is necessary only to irradiators with transport system based in carrier concept. In this concept the carriers are suspended 
and accommodate a wide range of product sizes. For irradiators with transport system based in product boxes, a protective shroud and product guides are more than sufficient to protect the sources.

\section{Source Travel Timer}

In order to identify a fault in the radioactive source movement, safety switches should indicate the full movement of the sources (up or down), which must be performed within a defined time interval. If any source rack does not finish its path within the expected range time, the system must indicate a fault and shutdown the irradiator. It has not been observed the existence of this sensor in the safety system of only one irradiator facility.

\section{Automatic Actuation Device}

In the oldest facilities some sensors are interlocked with the safety system, but they act automatically only to return the source to a safe condition, not performing additional actions, mainly:

$>$ The radiation monitor of water treatment system not stopping the circulation of water;

$>$ The product exit radiation monitor not stopping the system carrying product and;

$>$ The sprinkler valve in the fire protection system being manually open.

\section{Loss of External Power}

Two facilities in Brazil do not have uninterruptible power supply (UPS) system in order to allow safe shutdown in case of external power failure. Critical components in the safety system should be connected to an UPS system capable of providing the necessary electrical power for a controlled shutdown.

\section{System for Lowering the Source Rack}

A backup emergency system should be provided for lowering the source rack to the fully shielded position in the event of a failure of the cable or drive mechanism used to move the source racks. The IAEA recommend that for mechanical hoist systems, the backup system may be a manual brake release to allow the controlled descent of the source rack. In pneumatic systems, a second solenoid valve, in parallel with the main one, should be available. If the main valve fails to exhaust, the second valve should provide a means of exhausting air, thus allowing the source rack to descend into the fully shielded position [5]. It should be noted that the presence of this safety system is not observed in some of the irradiators in Brazil.

\section{Irradiator Pool}


The older ones facilities do not have a water-tight stainless steel liner, as recommended by IAEA, being tile coated pools. A cost-benefit analysis should be performed in order to define the need for change in the pool structure.

In addition, it should be noted that weekly assessments of the replenish water volume, in values above the estimates due to evaporation, may indicate the loss of pool water-tightness and the need for modifications in its structure.

\section{CONCLUSION}

It was carried out a diagnosis of safety systems of Brazilian irradiators, taking into account the national regulations and IAEA recommendations. In the next years, industrial irradiation facilities, with obsolete safety systems, should be upgraded, with the purpose of bringing their systems to the state of the art, thus a schedule for this specific action must be approved by the regulatory authority for each facility.

Some sensors of safety systems in oldest Brazilian industrial irradiators should be improved, basically for automatic actuation, thus the upgrade of control systems in irradiator facilities would use the advances in computer technology, and old control units based on relay logic would be replaced with a new one based on safety programmable logic controllers.

It should be emphasized that the operating organization must obtain the approval of the regulatory authority before implementing any modifications on the irradiator that may have significant implications for radiation protection [11].

\section{REFERENCES}

1. Gusev I., Guskova A. and Mettler F. A., Medical Management of Radiation Accidents Accidents at Industrial Irradiation Facilities, Second Edition, CRC Press, Boca Raton, 2001. p. 211-222.

2. Wang, Z. D. Continuous cytogenetic follow-up, over 5 years, of three individuals accidentally irradiated by a cobalt-60 source, Mutation Research/Genetic Toxicology and Environmental Mutagenesis, 779, p.1-4, 2015.

3. Ortiz P., Oresegun M., Wheatley J., Lessons from Major Radiation Accidents, In: 10th International Congress of the International Radiation Protection Association, Hiroshima, 2000. Available at http://www.irpa.net/irpa10/cdrom/00140.pdf>. Last accessed: 20 Dec. 2017.

4. IAEA - International Atomic Energy Agency, Lessons learned from accidents in industrial irradiation facilities, Vienna, 1996. 52p. 
5. IAEA - International Atomic Energy Agency, Radiation safety of gamma, electron and $x$ ray irradiation facilities. IAEA Specific Safety Guide SSG-8, Vienna, 2010, 112p.

6. Rodrigues Júnior A. A., Irradiadores Industriais e Sua Radioproteção, Author Edition Maringá, 2014.

7. Gruhn P. and Cheddie H., Safety Instrumented Systems: Design, Analysis, And Justification - 2nd Edition, ISA Triangle Park, 2006.

8. Howard A. and Stephan D., Upgrading Safety Systems in the Petrochemical Industry: Basic Guidelines, Process Worldwide, Vogel, Wurzburg, 2015.

9. CNEN - Comissão Nacional de Energia Nuclear. Diretrizes Básicas de Radioproteção. Norma CNEN-NN-3.01, CNEN, Rio de Janeiro, 2014. 22p.

10. CNEN - Comissão Nacional de Energia Nuclear. Serviços de Radioproteção. Norma CNENNE-3.02, CNEN, Rio de Janeiro Brazil, 1988. 17p.

11. CNEN - Comissão Nacional de Energia Nuclear. Licenciamento de Instalações Radiativas. Norma CNEN-NN-6.02, CNEN, Rio de Janeiro Brazil, 2014. 14p.

12. Drndarevic V., Control of Gamma Irradiation Facility with Improved Safety System, Journal of Nuclear Science and Technology, 45:4, p.361-367, 2008.

13. Calvo W., Rela P., Springer F. E., Costa F. E., Omi N. M. and Silva L. G. A., A small size continuous run industrial gamma irradiator, Radiation Physics and Chemistry, 71, p.561-563, 2004.

14. McKinney D., Perrins R., Gibson W., Levesque D., Brevion: the new small-scale industrial gamma irradiator. Radiation Physics and Chemistry, 63, p. 567-569, 2002.

15. Drndarevic, V. Safety Systems in Gamma Irradiation Facilities, Health Physics, 73(2), p. 383384, 1997.

16. AERB - Atomic Energy Regulatory Body. Radiation Processing Facilities. AERB Safety Code RF-RPF/SC-1, Mumbai, 2016, 57p. 